\title{
Simulation of radiation damage in gadolinium pyrochlores
}

\author{
Ilian T Todorov ${ }^{1,3}$, John A Purton ${ }^{1}$, Neil L Allan ${ }^{2}$ and Martin T Dove \\ ${ }^{1}$ CLRC, Daresbury Laboratory, Warrington WA4 4AD, UK \\ ${ }^{2}$ School of Chemistry, University of Bristol, Cantock's Close, Bristol BS8 1TS, UK \\ ${ }^{3}$ Department of Earth Sciences, University of Cambridge, Downing Street, Cambridge CB2 3EQ, \\ UK
}

Received 14 November 2005

Published 2 February 2006

Online at stacks.iop.org/JPhysCM/18/2217

\begin{abstract}
We report molecular dynamics simulations of the production of radiation cascades in pyrochlores. We consider the apparently similar systems $\mathrm{Gd}_{2} \mathrm{Ti}_{2} \mathrm{O}_{7}$, $\mathrm{Gd}_{2} \mathrm{Zr}_{2} \mathrm{O}_{7}$ and $\mathrm{Gd}_{2} \mathrm{~Pb}_{2} \mathrm{O}_{7}$, the first two of which have been put forward as potential materials for high-level radioactive waste storage. The effects of changing the mass of the 'primary knock-on' atom are also examined and we investigate whether the change in behaviour from $\mathrm{Ti}$ to $\mathrm{Zr}$ to $\mathrm{Pb}$ is largely due to the mass or the size difference between the elements. Problems associated with analysing the cascades and the damage created are discussed. There are clear differences between the three compounds. The simulations see no direct amorphization but rather a transition to the fluorite structure which is more pronounced for the $\mathrm{Zr}$ and $\mathrm{Pb}$ compounds than the $\mathrm{Ti}$ system. Underlying chemical trends are examined.
\end{abstract}

(Some figures in this article are in colour only in the electronic version)

\section{Introduction}

Radiation damage in pyrochlores has been of considerable interest ever since they have been proposed as possible materials for high-level radioactive waste storage. Disposal of the plutonium generated by the nuclear fuel cycle remains one of the daunting environmental challenges of this century $[1,2]$ since it is a long-lived environmental contaminant (half-life ${ }^{239} \mathrm{Pu} 24100$ years) and fissile, so that it decays to the longer-lived and fissile ${ }^{235} \mathrm{U}$ (halflife $7 \times 10^{8}$ years). Substantial amounts of $\mathrm{Pu}$ require immobilization in a solid matrix for geological disposal, together with other actinides such as $\mathrm{Np}$ and Am. The radionuclides need to be bound in an inert matrix capable of retaining its structural integrity during prolonged heavy particle bombardment at temperatures of 300-600 K. The identification of a suitable host matrix is contentious, with the pyrochlore $\mathrm{Gd}_{2} \mathrm{Ti}_{2} \mathrm{O}_{7}$ a primary candidate. Nevertheless, studies employing heavy ion bombardment [3] to simulate the effects of $\alpha$-decay have shown 
this compound undergoes amorphization at a dose corresponding to that of $\alpha$-decay damage, resulting in a subsequent ten-fold increase in the leach rate of $\mathrm{Pu}$. Wang et al [4] have also used heavy ion bombardment to demonstrate a striking variation in radiation tolerance in the series $\mathrm{Gd}_{2}\left(\mathrm{Zr}_{x} \mathrm{Ti}_{1-x}\right)_{2} \mathrm{O}_{7}(x=0-1)$. Increasing radiation tolerance was found with increasing $\mathrm{Zr}$ content such that $\mathrm{Gd}_{2} \mathrm{Zr}_{2} \mathrm{O}_{7}$ was predicted to withstand radiation damage for 30 million years compared with 800 years for $\mathrm{Gd}_{2} \mathrm{Ti}_{2} \mathrm{O}_{7}$. This is surprising in view of the chemical similarity of the Group 4 elements $\mathrm{Zr}$ and $\mathrm{Ti}$, and the $\mathrm{Gd}_{2}\left(\mathrm{Zr}_{x} \mathrm{Ti}_{1-x}\right)_{2} \mathrm{O}_{7}$ system and other pyrochlores have now received considerable experimental attention [5-11]. The Gd zirconate end member $(x=1)$ is indeed largely insensitive to irradiation damage remaining highly crystalline to high doses even at very low temperatures undergoing a radiation-induced transition to the (oxygendeficient) fluorite structure in which the $\mathrm{Gd}^{3+}$ and $\mathrm{Zr}^{4+}$ cations are disordered and which is itself highly radiation resistant. One of the purposes of this paper is to compare displacement cascades in $\mathrm{Gd}_{2} \mathrm{Ti}_{2} \mathrm{O}_{7}$ and $\mathrm{Gd}_{2} \mathrm{Zr}_{2} \mathrm{O}_{7}$, and we extend this comparison by presenting results for a further pyrochlore, $\mathrm{Gd}_{2} \mathrm{~Pb}_{2} \mathrm{O}_{7}$, for which we have been unable to find any experimental reports of the effects of radiation damage. A comprehensive recent review of pyrochlores in the context of nuclear waste disposal is that of Ewing et al [12].

Sickafus et al [13] have proposed that oxygen-deficient fluorites, with the same basic $\mathrm{A}_{2} \mathrm{~B}_{2} \mathrm{O}_{7}$ structure as pyrochlores but a random arrangement of the cations, have a greater propensity for resisting radiation damage (see also [14]). The lower the cation antisite defect energy (e.g., $\mathrm{Gd}_{2} \mathrm{Zr}_{2} \mathrm{O}_{7}$ ) the more readily will a transition under irradiation to the disordered fluorite structure take place and the more radiation resistant the compound. Alternatively, if the antisite defect is large (e.g., $\mathrm{Gd}_{2} \mathrm{Ti}_{2} \mathrm{O}_{7}$ ) then there is an irradiation-induced crystalline to amorphous transition. The cation antisite defect energies vary considerably with the radii of the $\mathrm{A}^{3+}$ and $\mathrm{B}^{4+}$ ions, and are smaller the closer these ions are in size, as developed in subsequent papers by Minervini et al $[15,16]$. The more similar the A and B cations, then the higher the capacity the system has for accommodating the antisite cation defect due to the lower antisite defect energy. Only when the free energy is larger than that of the amorphous material will the material be amorphized readily.

The correlation between calculated antisite point defect energies and behaviour under irradiation [13] is remarkably successful. For example, $\mathrm{La}_{2} \mathrm{Zr}_{2} \mathrm{O}_{7}$ is more susceptible [17] to ion-induced amorphization than $\mathrm{Gd}_{2} \mathrm{Zr}_{2} \mathrm{O}_{7}$, consistent with the larger size of $\mathrm{La}^{3+}$ (relative to $\mathrm{Gd}^{3+}$ ) and this correlation [13]. Unlike the other $\mathrm{Zr}$ pyrochlores, it appears [17] to undergo a transition under irradiation to the amorphized material at low temperatures (via disordered fluorite) while at high temperature the material remains as the disordered crystalline fluorite. The low-temperature behaviour shows that the fluorite structure by itself is not necessarily sufficient to prevent amorphization. Addition of the smaller Ce ion to $\mathrm{La}_{2} \mathrm{Zr}_{2} \mathrm{O}_{7}$ increases substantially the resistance to ion irradiation amorphization [18] in agreement with the suggested correlation. Covalency terms also seem to play a rôle as well as the relative size of the cations. Although there is only a very small difference in size between $\mathrm{Sn}^{4+}$ and $\mathrm{Hf}^{4+}, \mathrm{Gd}_{2} \mathrm{Sn}_{2} \mathrm{O}_{7}$ is more readily amorphized than $\mathrm{Gd}_{2} \mathrm{Hf}_{2} \mathrm{O}_{7}$. This has been attributed to the covalency of the $\mathrm{Sn}-\mathrm{O}$ interaction [19] with a preference for directional bonding which hinders the healing process [20]. While the static calculations provide highly valuable correlations, they do not take into account the complexity of the processes which are induced by irradiation. They cannot give a detailed description of the behaviour at the atomic level involved in these processes or allow for high concentrations of defects at high temperature. Weber et al [21], in addition, have emphasized the critical importance of the energy barrier to damage recovery rather than the fluorite structure itself. Thus in this paper we present the results of molecular dynamics simulations of displacement cascades for $\mathrm{Gd}_{2} \mathrm{X}_{2} \mathrm{O}_{7}(\mathrm{X}=\mathrm{Ti}, \mathrm{Zr}, \mathrm{Pb})$ and examine and compare key features of the primary damage state. 
Two types of particle irradiation [22] are responsible for the $\alpha$-decay damage. The first of these is the $\alpha$-particle or helium ion, with an energy of 4.5-5.8 MeV and a range of 10-30 $\mu \mathrm{m}$. The second is the recoil of the heavy actinide nucleus, which has an energy of 70-100 keV and a range of 10-20 $\mathrm{nm}$. To determine the amount of radiation damage it is important to establish whether each particle will transfer its energy to electrons (via electronic excitation and ionization) or to atomic nuclei by means of collisions. An $\alpha$-particle deposits its energy predominantly by ionization over its path with a limited number of collisions $(\sim 100)$ at the end of its trajectory; in contrast an $\alpha$-recoil ion will lose most of its energy by collisions producing up to several thousand atomic displacements.

The initial step in the radiation damage process is the production of a 'primary knock-on' atom (PKA). The PKA dissipates its energy through interactions with 'target' atoms and when the PKA has sufficient kinetic energy (and mass) an atomic collision cascade [22] results. One of our aims in this paper is to investigate the effect of the mass of the PKA on the damage. The subsequent evolution of the damage depends on the degree to which the stability of the lattice is altered by the accumulation of point defects (i.e. its propensity to amorphize under irradiation) and the ultimate fate of the irradiation-induced point defects, which can migrate and annihilate harmlessly or can cluster with other interstitials and vacancies to precipitate dislocation loops and voids. The final damaged state results from the initial cascade (timescale of femtoseconds), nearly instantaneous relaxation of the structure (picoseconds) and the thermal annealing (seconds).

Molecular dynamics (MD) simulations are well suited to studying atomic processes that operate on picosecond timescales. They have been used to study the formation of defect cascades in metals [23] but, despite studies of cascades in a waste glass [24] and in zircon [25], considerably less attention has been paid to the mechanism of damage production in displacement cascades in ceramics. The structure and the initial evolution of the radiationdamaged state are increasingly accessible with the computational resources now available. A recent molecular dynamics study [26] of cascades in $\mathrm{La}_{2} \mathrm{Zr}_{2} \mathrm{O}_{7}$, for example, suggests that the primary damage state in this compound is related to the fluorite structure and there is little amorphization; the single cascades in this study did not result in direct amorphization.

Here we investigate and compare the formation of cascades in $\mathrm{Gd}_{2} \mathrm{Ti}_{2} \mathrm{O}_{7}, \mathrm{Gd}_{2} \mathrm{Zr}_{2} \mathrm{O}_{7}$ and $\mathrm{Gd}_{2} \mathrm{~Pb}_{2} \mathrm{O}_{7}$. Are the differences between the cascades attributable chiefly to the different masses of $\mathrm{Ti}, \mathrm{Zr}$ and $\mathrm{Pb}$, the different sizes or the differences in bond strength? In addition, previous molecular dynamics work has generally generated a PKA simply by assigning a large kinetic energy to one of the ions in the parent compound (i.e., $\mathrm{Gd} / \mathrm{Ti} / \mathrm{Zr} / \mathrm{Pb} / \mathrm{O}$ ), thus ignoring that the PKA is almost always a foreign heavy atom such as uranium. Thus, we also examine the effect of the mass of the PKA to see if this simple procedure is a good assumption. Some important general issues associated with the analysis of the damage in the cascades generated in the simulations are also discussed.

\section{Theoretical methods}

We have used the DL_POLY_3 code [27], and have assumed an ionic model throughout, in which each ion is assigned its formal charge, i.e. $3+, 4+$ and $2-$ for $\mathrm{Gd}, \mathrm{Ti} / \mathrm{Zr}$ and $\mathrm{O}$ respectively. During a displacement cascade ions can approach each other very closely and it is vital to use potentials that are likely to be accurate over a wide range of internuclear separations and especially at short distances. The potentials used here have been calculated over a wide range of separations using a modified Gordon-Kim method [28]. These electron-gas potentials have been used previously in simulation studies of a wide range of binary and ternary oxides (e.g., high-temperature superconducting ceramics [29]) and have been particularly 
Table 1. Short range potential parameters. The form of the Buckingham potential is $V_{i j}=$ $A \exp \left(-r_{i j} / \rho\right)$.

\begin{tabular}{lrl}
\hline Interaction & \multicolumn{1}{l}{$A(\mathrm{eV})$} & $\rho(\AA)$ \\
\hline $\mathrm{O}-\mathrm{O}$ & 249.3764 & 0.3621 \\
$\mathrm{Ti}-\mathrm{O}$ & 3878.4225 & 0.2717 \\
$\mathrm{Gd}-\mathrm{O}$ & 4651.9633 & 0.2923 \\
$\mathrm{Zr}-\mathrm{O}$ & 8769.5930 & 0.2619 \\
$\mathrm{~Pb}-\mathrm{O}$ & 8721.4000 & 0.2607 \\
$\mathrm{U}-\mathrm{O}$ & 4792.4400 & 0.3009 \\
\hline
\end{tabular}

useful for problems involving defects where the interatomic distances close to the defect after relaxation may be very different from those in the perfect lattice at equilibrium [30]. The potential parameters for $\mathrm{O}-\mathrm{O}, \mathrm{Ti}-\mathrm{O}, \mathrm{Gd}-\mathrm{O}, \mathrm{Zr}-\mathrm{O}$ and $\mathrm{Pb}-\mathrm{O}$, collected together in table 1 , were generated by fitting an exponential of the form $A \exp (-r / \rho)$ (where $A$ and $\rho$ are constants) to the electron-gas interaction energies. For $\mathrm{U}-\mathrm{O}$, the potential listed in table 1 was obtained by fitting to the lattice parameter of $\mathrm{UO}_{2}$ transferring the $\mathrm{O}-\mathrm{O}$ potential already generated. A comparison of experimental lattice parameters and, where available, selected bond lengths for undefective $\mathrm{Gd}_{2} \mathrm{Ti}_{2} \mathrm{O}_{7}$ and $\mathrm{Gd}_{2} \mathrm{Zr}_{2} \mathrm{O}_{7}$ is given in [31]; for $\mathrm{Gd}_{2} \mathrm{~Pb}_{2} \mathrm{O}_{7}$ the lattice parameter calculated using energy minimization in the static limit and the SHELL code is $10.735 \AA$ which compares with the one experimental value we have been able to find [32] of $10.716 \AA$ (for a sample prepared by high-pressure synthesis); no bond lengths are available for comparison. Very recently Devanathan and Weber have used potentials for the Ti and Zr compounds very similar to our own [33].

In the molecular dynamics simulations, for PKAs with energies $E \leqslant 3 \mathrm{keV}, 3 \mathrm{keV}<$ $E<10 \mathrm{keV}$ and $E=10 \mathrm{keV}$ cubic simulation cells of 88000,152064 and 193336 atoms were used, respectively. These large cell sizes are such that a cascade does not interact with its periodic images for all practical purposes. Initial simulation cell lengths were set to the appropriate multiple of the experimental lattice parameter, corresponding to 10,12 and 13 unit cells in each direction, respectively. The initial temperature of the simulation was set to $300 \mathrm{~K}$ and the simulation was allowed to equilibrate for $10 \mathrm{ps}$ within the NPT-ensemble, using a timestep of $2 \mathrm{fs}$. Unless specified otherwise below, and unlike in the previous work of two of us [31], all simulations used for the PKA a $U$ atom substituted for a native Gd ion.

The production of a cascade was then started from the energetic recoil of a single atom, the PKA, and the subsequent collisions, displacements and recombination of atoms with vacant sites followed, so that the complete structure and evolution of the cascade could be monitored. In contrast to the fixed timestep of $0.5 \mathrm{fs}$ used in all simulations reported in an earlier preliminary account of cascades in these two pyrochlores [31], the extra computational resources now available to us have enabled us to use a variable timestep. The variable timestep method, as developed in DL_POLY_3, relies on two user-specified distances $D_{\min }$ and $D_{\max }$ (default values 0.03 and $0.10 \AA$ respectively) which are used to control the timestep length during a simulation. At the end of each timestep the algorithm compares the greatest distance a particle has travelled during the integration with the control distances. If $D_{\max }$ is exceeded, the integration is rewound back a timestep, the timestep length is then halved and the integration step repeated. If the largest move is less than $D_{\min }$, the integration is rewound, then the timestep length is doubled and the integration step repeated. In this way the integration timestep selfadjusts in response to the dynamics of the system. We shall see that such a variable timestep is particularly important due to the high energy of the PKA, and quantitatively our results differ from those in the preliminary study [31]. 
Table 2. A comparison of structural damage data from a $10 \mathrm{keV}$ cascade in $\mathrm{Gd}_{2} \mathrm{Zr}_{2} \mathrm{O}_{7}$ with a $\mathrm{U}$ PKA of different masses directed along [111].

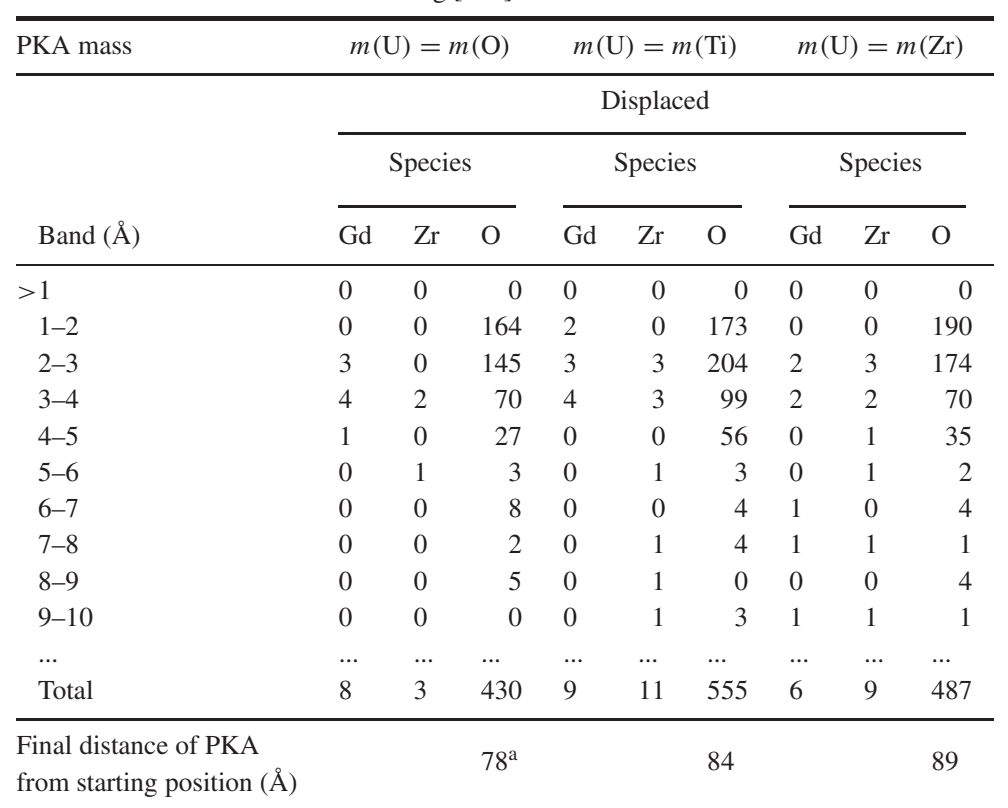

a The maximum distance of this very light PKA from the starting point during the simulation was $91 \AA$ A. For the heavier PKAs the final distance is also the maximum distance from the start.

The creation of a radiation cascade results in an initial sharp rise in the global temperature of the simulation cell, no larger than $1150 \mathrm{~K}$ for the simulation cells in this paper, and the temperature then decreases during the simulation. Timestep lengths vary during the development of a cascade. Typically for the $10 \mathrm{keV}$ cascades reported in this paper, timesteps are very short (approximately a few atoseconds) at the beginning of the cascade simulation (up to $0.25 \mathrm{ps}$ ) and remain relatively unchanged at a few femtoseconds towards the end (8-12 ps).

\section{Results and discussion}

\section{PKA mass}

Previous workers have largely neglected the mass of the PKA, often simply making a host ion of any type the PKA. To examine the possible influence of the mass of the PKA we have carried out a series of simulations on $\mathrm{Gd}_{2} \mathrm{Zr}_{2} \mathrm{O}_{7}$ with a PKA of $5 \mathrm{keV}$ and a simulation cell size of 152064 ions. Instead of choosing a Gd or $\mathrm{Zr}$ host atom as the PKA we have explicitly replaced $\mathrm{Gd}^{3+}$ with a $\mathrm{U}^{3+}$ ion. The use of this charge state for $\mathrm{U}$ removes the need for any compensating defect. A subsequent run used for the PKA a hypothetical atom ('light uranium') with the same interatomic potentials as $U$ but with the mass of $\mathrm{Gd}$ (a $30 \%$ reduction). In table 2 is listed the structural damage from three cascades in the [111] direction each with a different PKA mass. The numbers of each type of atom which have been displaced by a given distance are tabulated, together with the total distance travelled by the PKA.

The heavier the PKA, the further it travels. The total number of atoms displaced also varies with this quantity, increasing from increasing the mass from that of $\mathrm{O}$ to that of Ti. When the PKA has the mass of $\mathrm{Zr}$, it now has the same mass as that of a host ion. Classical mechanics indicates that the energy transfer between the PKA and the host ion is a maximum in this 

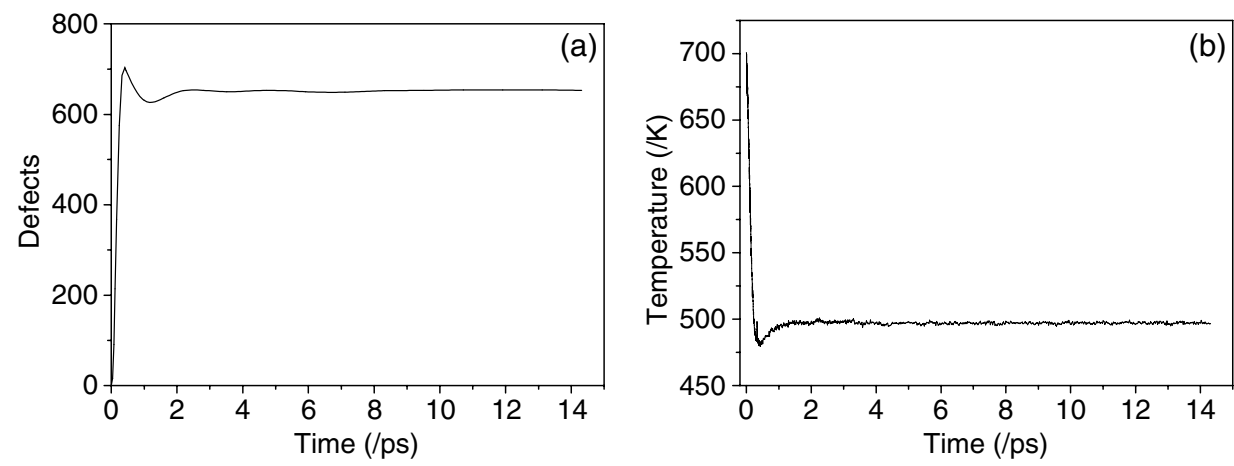

Figure 1. Total number of 'defects' (a) and instantaneous temperature (K) (b) as a function of time after the creation of a PKA for a single simulation of $\mathrm{Gd}_{2} \mathrm{Zr}_{2} \mathrm{O}_{7}$ with initial temperature $300 \mathrm{~K}$. The $10 \mathrm{keV}$ PKA was a U ion in this case. As discussed in the text we here define a 'defect' as an ion that has moved more than half the average of the first-neighbour interatomic distances.

case, and this may be responsible for the smaller total number of displaced atoms generated here. When the PKA is very light it bounces off the other atoms during the cascade, changing direction frequently as it rebounds. Thus the shape of the cascades must be different for the lightest PKA, being more elongated for the heavier species. This may have implications for the further evolution of the system. Overall, it does appear important to assign the appropriate mass to the PKA rather than choose a host ion at random.

\section{Damage}

The cascades can be usefully analysed in several different ways but a key quantity of interest is the number of defects created as a function of the PKA energy. We note in passing that the behaviour of metals is quite different so that cascades in such systems can be analysed in terms of point defect assemblies. We first define, following reference [23], a 'defect' in terms of displacements, i.e., as an ion that has moved more than half the average of the firstneighbour interatomic distances. This is determined with respect to the position of an ion after the equilibration phase of the simulation. Alternative definitions are considered later.

It is possible that the duration of the subsequent simulation of the cascade might influence the number of 'defects' thus calculated if the simulation is truncated prematurely, and so the number of such 'defects' was monitored as a function of time. In figure 1(a) we show the results of a single simulation for $\mathrm{Gd}_{2} \mathrm{Zr}_{2} \mathrm{O}_{7}$, using a PKA of $10 \mathrm{keV}$ (the highest energy considered in this study), and it is evident that after approximately 5 ps the number of 'defects' remains effectively constant. Temperature is shown as a function of time for this simulation in figure 1(b). Note that the number of 'defects' is greater and the final temperature has a larger value than that reported previously [31] (note there is also a typographical error in the caption to figure 1(b) in [31], which should have stated that the PKA was $5 \mathrm{keV}$ ). This is due to the use here of a variable timestep which allows a far more accurate evolution of the system at the start of the simulation where the PKA has lost little of its initial kinetic energy. With too large a fixed timestep at this early stage, the PKA moves too far at each step without interacting with its immediate surroundings, which may create less damage or may result in the PKA adopting an unphysical position too close to another ion. We stress though that all the conclusions of [31] remain unchanged, since the same qualitative trends are seen throughout using both variable and fixed timesteps. 


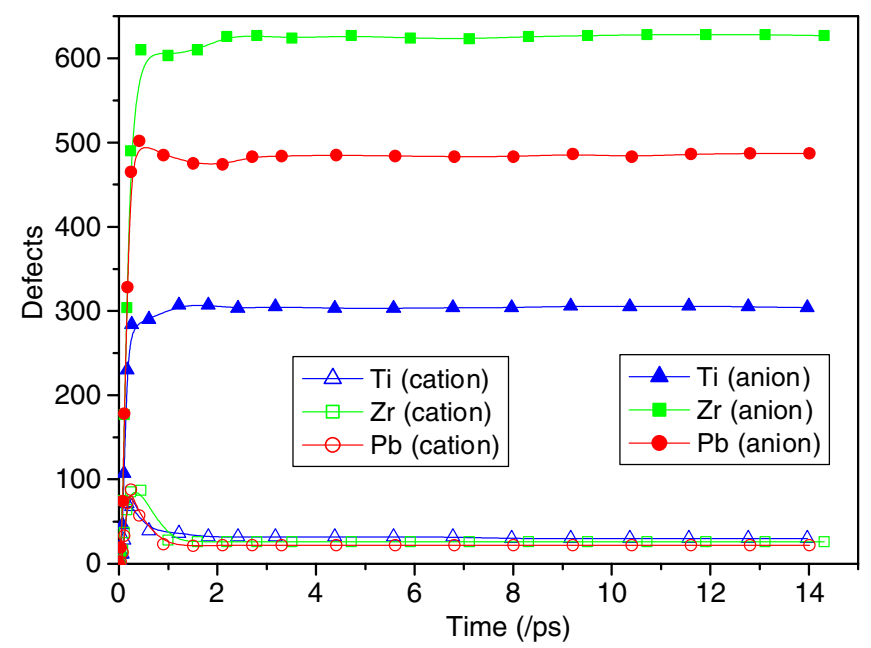

Figure 2. Instantaneous number of 'defects' plotted as a function of time during a $10 \mathrm{keV}$ cascade (U PKA) in the Ti, $\mathrm{Zr}$ and $\mathrm{Pb}$ pyrochlores ( $\mathrm{Gd}-\mathrm{Ti}-\mathrm{O}$ triangles, $\mathrm{Gd}-\mathrm{Zr}-\mathrm{O}$ squares and $\mathrm{Gd}-\mathrm{Pb}-\mathrm{O}$ circles). There are separate plots for the damage on the cation (empty symbols) and anion (filled symbols) sublattices. The definition of a 'defect' is as in figure 1 .

To investigate whether defect diffusion takes place after the number of 'defects' is effectively constant, we have carried out a series of NPT-simulations on $\mathrm{Gd}_{2} \mathrm{Zr}_{2} \mathrm{O}_{7}, \mathrm{Gd}_{2} \mathrm{Ti}_{2} \mathrm{O}_{7}$ and $\mathrm{Gd}_{2} \mathrm{~Pb}_{2} \mathrm{O}_{7}$ (20 ps duration) and determined the limiting value of the mean-square displacement over a range of temperatures considerably wider than the variation of the global temperature of the cell (figure 1(b)). These indicate that self-diffusion processes are negligible after the final formation of the cascade and therefore do not influence the number of defects on this relatively short timescale.

Since each cascade is different, it is necessary to simulate as many cascades as possible in order to collect reasonable statistics and identify trends. Unfortunately, limitations in computer resources hinder this objective (especially for the largest cell used in this study). In this study we assessed the damage for a given energy of a PKA by simulating cascades with the PKA headed along all body-diagonals of the MD cell (eight directions).

For a given PKA energy the number of 'defects' decreases in the order $\mathrm{Gd}_{2} \mathrm{Zr}_{2} \mathrm{O}_{7}>$ $\mathrm{Gd}_{2} \mathrm{~Pb}_{2} \mathrm{O}_{7}>\mathrm{Gd}_{2} \mathrm{Ti}_{2} \mathrm{O}_{7}$. For example, this is evident from figure 2, which plots the running total of 'defects' as a function of time during a $10 \mathrm{keV}$ cascade. It would of course be possible to use an alternative definition of a 'defect' with a different displacement. We examined several distances $\geqslant 1 \AA$. The number of 'defects' decreases with increasing cutoff but qualitative differences between the three compounds remain unchanged. We discuss these apparent trends in more detail below.

In tables 3 and 4 we summarize the structural damage which results from the $10 \mathrm{keV}$ cascades in $\mathrm{Gd}_{2} \mathrm{Ti}_{2} \mathrm{O}_{7}$ and $\mathrm{Gd}_{2} \mathrm{Zr}_{2} \mathrm{O}_{7}$ starting at $300 \mathrm{~K}$ and zero pressure. Results are presented both for a typical cascade in the $\langle 111\rangle$ direction and mean values of eight cascades, one in each body-diagonal direction. The numbers of each type of atom which have been displaced by a given distance are listed, together with the total distance travelled by the PKA. Examining the totals in the final rows of these two tables, it is clear that more atoms are displaced in the $\mathrm{Zr}$ than the Ti compound. Note also that the PKA has travelled further in the $\mathrm{Zr}$ case, and fewer heavier $\mathrm{Zr}$ ions are displaced in the $\mathrm{Zr}$ compound than lighter Ti ions are displaced in the Ti compound. Thus the number of cations displaced is comparable in the two compounds, while more anions 
Table 3. Structural damage data from $10 \mathrm{keV}$ cascades in $\mathrm{Gd}_{2} \mathrm{Ti}_{2} \mathrm{O}_{7}$ at $300 \mathrm{~K}$ and zero pressure. The PKA is a $\mathrm{U}$ ion. The table lists how many atoms of each species have moved a particular distance given in the first column from their original lattice positions. The second column is for one cascade in the [111] ('body-diagonal') direction, while the third column lists the mean values for all eight cascades in $\langle 111\rangle$ directions.

\begin{tabular}{|c|c|c|c|c|c|c|}
\hline \multirow{4}{*}{$\begin{array}{l}\text { PKA direction } \\
\text { Band }(\AA)\end{array}$} & \multicolumn{4}{|c|}{ [111] direction } & \multicolumn{2}{|l|}{$\langle 111\rangle$} \\
\hline & \multicolumn{6}{|c|}{ Displaced } \\
\hline & \multicolumn{3}{|c|}{ Species } & \multicolumn{3}{|c|}{ Species } \\
\hline & Gd & $\mathrm{Ti}$ & $\mathrm{O}$ & $\mathrm{Gd}$ & $\mathrm{Ti}$ & $\mathrm{O}$ \\
\hline$>1$ & 0 & 0 & 0 & 0 & 0 & 0 \\
\hline $1-2$ & 0 & 3 & 2 & 0 & 1 & 6 \\
\hline $2-3$ & 1 & 3 & 242 & 1 & 2 & 212 \\
\hline $3-4$ & 13 & 14 & 63 & 8 & 8 & 49 \\
\hline $4-5$ & 0 & 1 & 42 & 0.5 & 1 & 30 \\
\hline $5-6$ & 0 & 0 & 15 & 0 & 0.5 & 13 \\
\hline $6-7$ & 0 & 2 & 5 & 0.3 & 0.8 & 4 \\
\hline $7-8$ & 0 & 1 & 5 & 0 & 0.8 & 4 \\
\hline $8-9$ & 0 & 0 & 1 & 0.5 & 0 & 3 \\
\hline $9-10$ & 0 & 0 & 1 & 0 & 0 & 1 \\
\hline$\cdots$ & $\ldots$ & $\ldots$ & $\ldots$ & $\ldots$ & $\ldots$ & $\ldots$ \\
\hline Total & 14 & 24 & 385 & 11 & 15 & 329 \\
\hline $\begin{array}{l}\text { Final distance of PKA } \\
\text { from starting position }(\AA)\end{array}$ & & & 100 & & & 84 \\
\hline
\end{tabular}

are displaced in the $\mathrm{Zr}$ pyrochlore. At first sight, this appears to be in conflict with results from high-energy ion bombardment experiments [4], where the resistance to amorphization in $\mathrm{Gd}_{2} \mathrm{Ti}_{2-X} \mathrm{Zr}_{X} \mathrm{O}_{7}$ increases with increasing $\mathrm{Zr}$ content.

We have therefore examined the damage distribution in more detail. We note first that the increase in damage on the oxygen sublattice is largely due to a substantial increase in the $\mathrm{Zr}$ compound of the numbers of $\mathrm{O}$ ions moving between 1 and $2 \AA$ (by over 150) and between 3 and $4 \AA$, relative to those in the Ti compound. The numbers of oxygen atoms moving between 2 and $3 \AA$ or more than $4 \AA$ from their initial positions are comparable.

Replacing Ti with $\mathrm{Zr}$ not only alters the transition-metal-oxygen bond strength but also the mass of this constituent. An advantage of computation is that we can attempt to separate out these two effects by changing only one of these two factors in the simulations. Table 5 lists the calculated displacements in hypothetical $\mathrm{Gd}_{2} \mathrm{Ti}_{2}^{*} \mathrm{O}_{7}$ where $\mathrm{Ti}^{*}$ has the same mass as $\mathrm{Zr}$ but interacts via the same potentials as Ti. In the hypothetical compound the total damage is much less (by approximately 30\%) and the PKA has travelled less, as one might have expected, but the pattern of damage as a function of distance is essentially the same in the $\mathrm{Ti}$ and $\mathrm{Ti}^{*}$ compounds, and does not change to resemble that in the Zr system (table 4). Similarly, table 6 presents structural damage data cascades in hypothetical $\mathrm{Gd}_{2} \mathrm{Zr}_{2}^{\dagger} \mathrm{O}_{7}$ with $\mathrm{Zr}^{\dagger}$ having the relative atomic mass of $\mathrm{Ti}, \mathrm{Gd}_{2} \mathrm{Zr}_{2} \mathrm{O}_{7}$ itself and $\mathrm{Gd}_{2} \mathrm{Zr}_{2}^{*} \mathrm{O}_{7}$, where $\mathrm{Zr}^{*}$ has the relative atomic mass of $\mathrm{U}$. The PKA travels the same distance in all three compounds and we see the same general trends. Increasing the mass of the $\mathrm{Zr}$ atom decreases the damage but again the pattern and distancedistribution of the damage is unchanged. Note also that there is an apparent asymmetry in the variation of the cation damage with mass. Decreasing the mass of $\mathrm{Zr}$ does not affect the number of $\mathrm{Gd}$ ions displaced while increasing it to that of $U$ leads to markedly less damage on the Gd sublattice. In this general context it is interesting to note that correlations such as that 
Table 4. Structural damage data from $10 \mathrm{keV}$ cascades in $\mathrm{Gd}_{2} \mathrm{Zr}_{2} \mathrm{O}_{7}$ at $300 \mathrm{~K}$ and zero pressure. The PKA is a $\mathrm{U}$ ion. The table lists how many atoms of each species have moved a particular distance given in the first column from their original lattice positions. The second column is for one cascade in the [111] ('body-diagonal') direction, while the third column lists the mean values for all eight cascades in $\langle 111\rangle$ directions.

\begin{tabular}{|c|c|c|c|c|c|c|}
\hline \multirow{4}{*}{$\begin{array}{l}\text { PKA direction } \\
\text { Band }(\AA)\end{array}$} & \multicolumn{4}{|c|}{ [111] direction } & \multicolumn{2}{|l|}{$\langle 111\rangle$} \\
\hline & \multicolumn{6}{|c|}{ Displaced } \\
\hline & \multicolumn{3}{|c|}{ Species } & \multicolumn{3}{|c|}{ Species } \\
\hline & $\mathrm{Gd}$ & $\mathrm{Zr}$ & $\mathrm{O}$ & $\mathrm{Gd}$ & $\mathrm{Zr}$ & $\mathrm{O}$ \\
\hline$>1$ & 0 & 0 & 0 & 0 & 0 & 0 \\
\hline $1-2$ & 0 & 0 & 166 & 0.3 & 0 & 153 \\
\hline $2-3$ & 4 & 3 & 211 & 3 & 2 & 232 \\
\hline $3-4$ & 5 & 2 & 120 & 6 & 6 & 132 \\
\hline $4-5$ & 4 & 2 & 48 & 3 & 2 & 51 \\
\hline $5-6$ & 1 & 1 & 15 & 0.8 & 1 & 18 \\
\hline $6-7$ & 1 & 0 & 11 & 0.8 & 1 & 8 \\
\hline $7-8$ & 0 & 0 & 0 & 0 & 0 & 2 \\
\hline $8-9$ & 0 & 1 & 3 & 0.5 & 0.3 & 2 \\
\hline $9-10$ & 0 & 0 & 2 & 0 & 0 & 1 \\
\hline$\ldots$ & $\ldots$ & $\ldots$ & $\ldots$ & $\ldots$ & $\ldots$ & $\ldots$ \\
\hline Total & 15 & 10 & 585 & 15 & 12 & 610 \\
\hline $\begin{array}{l}\text { Final distance of PKA } \\
\text { from starting position }(\AA)\end{array}$ & & & 104 & & & 95 \\
\hline
\end{tabular}

Table 5. Structural damage data from a $10 \mathrm{keV}$ cascade at $300 \mathrm{~K}$ and zero pressure with an U PKA initially directed along the [111] direction in (i) $\mathrm{Gd}_{2} \mathrm{Ti}_{2} \mathrm{O}_{7}$, and (ii) $\mathrm{Gd}_{2} \mathrm{Ti}_{2}^{*} \mathrm{O}_{7}$, with $\mathrm{Ti}^{*}$ having the relative atomic mass of $\mathrm{Zr}$.

\begin{tabular}{|c|c|c|c|c|c|c|}
\hline \multirow[b]{3}{*}{ Band $(\AA)$} & \multicolumn{6}{|c|}{ Displaced } \\
\hline & \multicolumn{3}{|c|}{ Species } & \multicolumn{3}{|c|}{ Species } \\
\hline & $\mathrm{Gd}$ & $\mathrm{Ti}$ & $\mathrm{O}$ & $\mathrm{Gd}$ & $\mathrm{Ti}^{*}$ & $\mathrm{O}$ \\
\hline$>1$ & 0 & 0 & 0 & 0 & 0 & 0 \\
\hline $1-2$ & 0 & 3 & 2 & 0 & 3 & 8 \\
\hline $2-3$ & 1 & 3 & 242 & 1 & 2 & 173 \\
\hline $3-4$ & 13 & 14 & 63 & 7 & 9 & 50 \\
\hline $4-5$ & 0 & 1 & 42 & 0 & 0 & 32 \\
\hline $5-6$ & 0 & 0 & 15 & 3 & 0 & 14 \\
\hline $6-7$ & 0 & 2 & 5 & 0 & 0 & 3 \\
\hline $7-8$ & 0 & 1 & 5 & 0 & 0 & 3 \\
\hline $8-9$ & 0 & 0 & 1 & 0 & 0 & 1 \\
\hline $9-10$ & 0 & 0 & 1 & 0 & 0 & 0 \\
\hline$\ldots$ & $\ldots$ & $\ldots$ & $\ldots$ & $\ldots$ & $\ldots$ & $\ldots$ \\
\hline Total & 14 & 24 & 385 & 11 & 15 & 290 \\
\hline $\begin{array}{l}\text { Final distance of PKA } \\
\text { from starting position }(\AA)\end{array}$ & & & 100 & & & 84 \\
\hline
\end{tabular}

suggested in [13] which are based on point defect energies are independent of the masses of the constituent ions and so cannot contain all the underlying physical quantities of importance. 
Table 6. Structural damage data from a $10 \mathrm{keV}$ cascade at $300 \mathrm{~K}$ and zero pressure with an U PKA initially directed along the [111] direction in (i) $\mathrm{Gd}_{2} \mathrm{Zr}_{2}^{\dagger} \mathrm{O}_{7}$ with $\mathrm{Zr}^{\dagger}$ having the relative atomic mass of $\mathrm{Ti}$, (ii) $\mathrm{Gd}_{2} \mathrm{Zr}_{2} \mathrm{O}_{7}$, and (iii) $\mathrm{Gd}_{2} \mathrm{Zr}_{2}^{*} \mathrm{O}_{7}$, with $\mathrm{Zr}^{*}$ having the relative atomic mass of $\mathrm{U}$.

\begin{tabular}{|c|c|c|c|c|c|c|c|c|c|}
\hline \multirow[b]{3}{*}{ Band $(\AA)$} & \multicolumn{9}{|c|}{ Displaced } \\
\hline & \multicolumn{3}{|c|}{ Species } & \multicolumn{3}{|c|}{ Species } & \multicolumn{3}{|c|}{ Species } \\
\hline & Gd & $\mathrm{Zr}^{\dagger}$ & $\mathrm{O}$ & $\mathrm{Gd}$ & $\mathrm{Zr}$ & $\mathrm{O}$ & $\mathrm{Gd}$ & $\mathrm{Zr}^{*}$ & $\mathrm{O}$ \\
\hline$>1$ & 0 & 0 & 0 & 0 & 0 & 0 & 0 & 0 & 0 \\
\hline $1-2$ & 0 & 0 & 127 & 0 & 0 & 166 & 1 & 0 & 160 \\
\hline $2-3$ & 2 & 3 & 251 & 4 & 3 & 211 & 2 & 3 & 167 \\
\hline $3-4$ & 9 & 9 & 155 & 5 & 2 & 120 & 6 & 2 & 124 \\
\hline $4-5$ & 2 & 2 & 53 & 4 & 2 & 48 & 0 & 0 & 40 \\
\hline $5-6$ & 1 & 1 & 23 & 1 & 1 & 15 & 0 & 2 & 8 \\
\hline $6-7$ & 1 & 0 & 18 & 1 & 0 & 11 & 0 & 1 & 2 \\
\hline $7-8$ & 0 & 0 & 3 & 0 & 0 & 0 & 0 & 0 & 1 \\
\hline $8-9$ & 0 & 1 & 4 & 0 & 1 & 3 & 0 & 0 & 4 \\
\hline $9-10$ & 0 & 1 & 0 & 0 & 0 & 2 & 0 & 0 & 1 \\
\hline$\ldots$ & $\ldots$ & $\ldots$ & $\ldots$ & $\ldots$ & $\ldots$ & $\ldots$ & $\ldots$ & $\ldots$ & $\ldots$ \\
\hline Total & 15 & 18 & 641 & 15 & 10 & 585 & 9 & 10 & 519 \\
\hline $\begin{array}{l}\text { Distance travelled } \\
\text { By PKA }(\AA)\end{array}$ & & & 103 & & & 104 & & & 102 \\
\hline
\end{tabular}

We thus have available a range of data comparing the damage caused by the cascades in the three compounds. We see a variety of behaviour by simply calculating how many atoms have moved a given distance. But this variety itself presents a problem of interpretation. As we have seen, comparing the cascades for the $\mathrm{Zr}$ and $\mathrm{Ti}$ compounds in tables 3 and 4, there is approximately equal cation damage but more anion damage overall in the $\mathrm{Zr}$ system. Even just considering the oxygen sublattice, there are more displacements at short distances and less at greater distances in the $\mathrm{Zr}$ compound than in the Ti analogue. This makes any overall correlation between the simulated cascades and the observed degree of amorphization difficult to establish, and a more complex issue than anticipated in [31].

We can obtain further insight into the oxygen disorder after each cascade by plotting the number of ions displaced versus distance rather than tabulating this information in broad bands such as in tables 2-5. This plot is shown in figure 3 for the three materials, and it is clear that this plot is highly structured with well defined peaks up to approximately $6 \AA$ for each compound. The differences in the number of atoms displaced at short distances $(<2.7 \AA)$ between the $\mathrm{Zr}$ and Ti compounds are particularly striking in this figure, with pronounced peaks at just below and just above $2 \AA$ for the former which are almost completely absent in the curve for the latter. Many oxygens are thus displaced a small amount in the $\mathrm{Zr}$ compound. The differences in the two curves for larger displacement distances $(>3.5 \AA)$ are smaller and the sign of the difference between the two curves changes with distance.

It is also potentially instructive to consider not just the displacements of individual ions but to consider the structure of the damaged compound itself. We first do this by looking at the final cascade and looking at the number of atoms not located at lattice sites. This is achieved by a new defect detection algorithm recently implemented in DL_POLY_3 by one of us (ITT). The algorithm compares the simulated MD cell to a reference MD cell. The former defines the actual positions of the particles and their atom types and the latter is taken here to be the structure of the undamaged lattice. If a particle, $p$, is located in the vicinity of a site, $s$, defined 


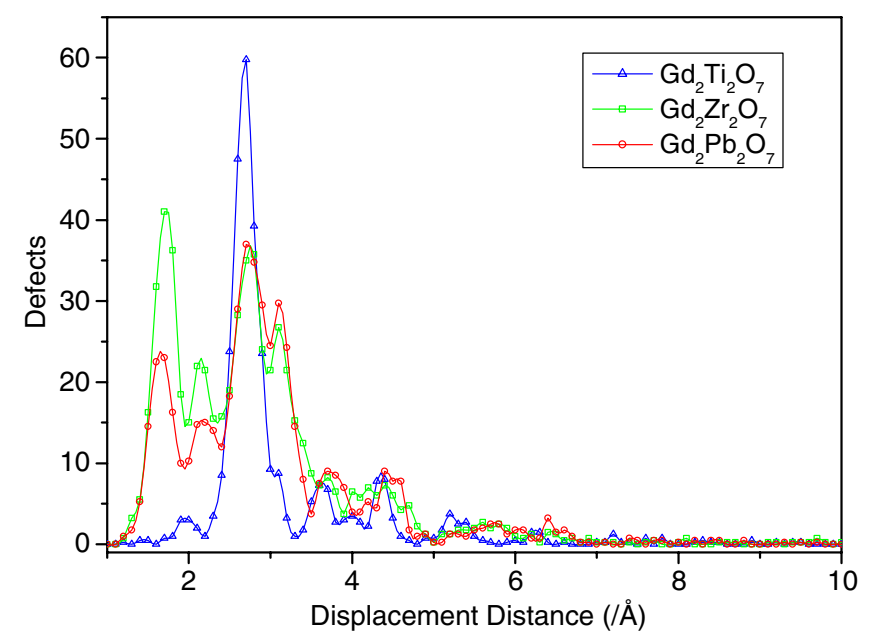

Figure 3. Mean final number of oxide ions displaced as a function of distance moved for all $10 \mathrm{keV}$ cascades ( $\mathrm{U}$ PKA) in the $\mathrm{Ti}, \mathrm{Zr}$ and $\mathrm{Pb}$ pyrochlores ( $\mathrm{Gd}-\mathrm{Ti}-\mathrm{O}$ triangles, $\mathrm{Gd}-\mathrm{Zr}-\mathrm{O}$ squares and $\mathrm{Gd}-\mathrm{Pb}-\mathrm{O}$ circles).

by a sphere with its centre at this site and a user-defined radius, $0.3 \AA \leqslant R_{\text {def }} \leqslant 1.3 \AA$ (default value $0.75 \AA$ ), then the particles is a first hand claimee of $s$, and the site is not vacant. Otherwise the site is presumed vacant and the particle is presumed a general interstitial. If a site, $s$, is claimed and another particle, $p^{\prime}$, is located within the sphere around it, then $p^{\prime}$ becomes an interstitial associated with $s$. After all particles and all sites are considered, it is clear which sites are vacancies. Finally, for every claimed site, distances between the site and its first hand claimee and interstitials are compared and the particle with the shortest one becomes the real claimee. If a first hand claimee of $s$ is not the real claimee it becomes an interstitial associated with $s$. At this stage it is clear which particles are interstitials. The sum of interstitials and vacancies gives the total number of defects in the simulated MD cell. Note that the algorithm cannot be applied safely if $R_{\mathrm{def}}$ is larger than half the shortest interatomic distance within the reference MD cell since a particle may (i) claim more than one site, (ii) be an interstitial associated with more than one site, or both (i) and (ii). Low values of $R_{\text {def }}$ are likely to lead to slight overestimation of the number of defects. If the simulation and reference MD cell have the same number of atoms then the total number of interstitials is always equal to the total number of defects.

This algorithm avoids the previous somewhat arbitrary definition of a defect in terms of displacements. Table 7 lists the number of defects, both interstitials and vacancies, defined in this new way, in the simulation cell (193336 atoms) for a PKA of $10 \mathrm{eV}$ for each of the three pyrochlores. The numbers of interstitial defects are now of course much smaller but the variation from one atom type to another and from one compound to another are the same as for the totals of each atom type displaced in each compound (e.g., tables 3 and 4).

A measure based on a point defect description will be misleading for example in the presence of dislocation-type extended defects since every atom associated with the extended defect will count towards the defect total even in a region where there is significant local order. This consideration has led to a calculation of the oxygen-oxygen radial distribution functions (RDFs) for the undamaged and damaged materials. These and the differences between the two are shown in figures 4(a)-(c). A comparison of figures 3 and 4 shows that although various oxygen atoms move by a small amount this does not mean that there are any such short oxygen- 

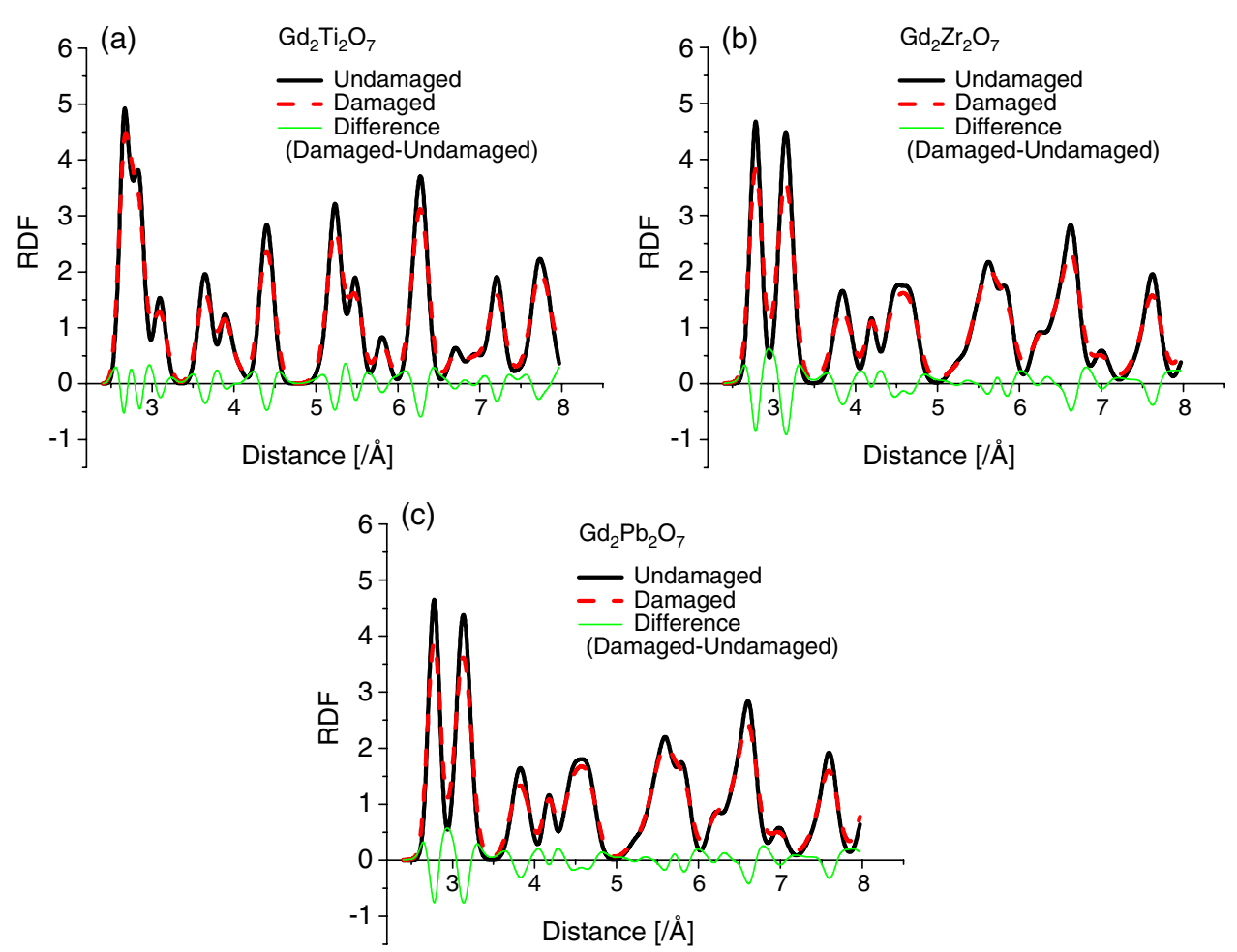

Figure 4. (a)-(c) Calculated oxygen-oxygen radial distribution functions (RDFs) for the three undamaged (thick solid line, black) and damaged (dashed line, red) pyrochlores. In each plot the difference between the undamaged and damaged RDFs is also plotted (thin solid line, green).

Table 7. Final number of interstitials and vacancies by atom type and antisite defects in the simulation cell associated with cascades in each pyrochlore $\mathrm{Gd}_{2} \mathrm{X}_{2} \mathrm{O}_{7}(\mathrm{X}=\mathrm{Ti}, \mathrm{Zr}, \mathrm{Pb})$ for a PKA of $10 \mathrm{keV}$ with initial temperature $300 \mathrm{~K}$. The final column for oxygen interstitials (headed Int') is the total number recalculated for the three compounds classifying the $8 \mathrm{a}$ site as a lattice rather than interstitial site, as described in the text.

\begin{tabular}{|c|c|c|c|c|c|c|c|c|}
\hline \multirow[b]{3}{*}{ Compound } & \multicolumn{8}{|c|}{ Defects } \\
\hline & \multicolumn{2}{|c|}{$\mathrm{Gd}$} & \multicolumn{2}{|c|}{$\mathrm{X}$} & \multicolumn{3}{|c|}{$\mathrm{O}$} & \multirow[b]{2}{*}{$\mathrm{Gd}-\mathrm{X}$} \\
\hline & Int & Vac & Int & Vac & Int & Vac & Int $^{\prime}$ & \\
\hline $\mathrm{X}=\mathrm{Ti}$ & 2.3 & 2.8 & 4.0 & 3.0 & 16.0 & 16.5 & 15.8 & 8.3 \\
\hline $\mathrm{X}=\mathrm{Zr}$ & 4.3 & 5.0 & 3.3 & 2.8 & 244.0 & 243.8 & 74.8 & 12.0 \\
\hline $\mathrm{X}=\mathrm{Pb}$ & 4.5 & 4.3 & 3.0 & 3.3 & 165.5 & 165.5 & 11.0 & 8.8 \\
\hline
\end{tabular}

oxygen separations in the damaged materials. Overall, as indicated by the sharp negative peaks in figure 4 , there is a loss of order and there are clear differences between the $\mathrm{Ti}$ and $\mathrm{Zr}$ compounds. One way of investigating this a little more quantitatively is to sum the absolute values of the areas under the difference curves in figure 4 for each compound. In figure 5 the integral of the absolute difference between the oxygen-oxygen RDFs of the undamaged and damaged material is plotted as a function of distance. There is a larger loss of order in the Zr pyrochlore at shorter separations (3-5 $\AA$ ), whereas at larger distances there appears to be a slightly larger loss of order for the Ti compound. The total integral is approximately $2 \%$ larger 


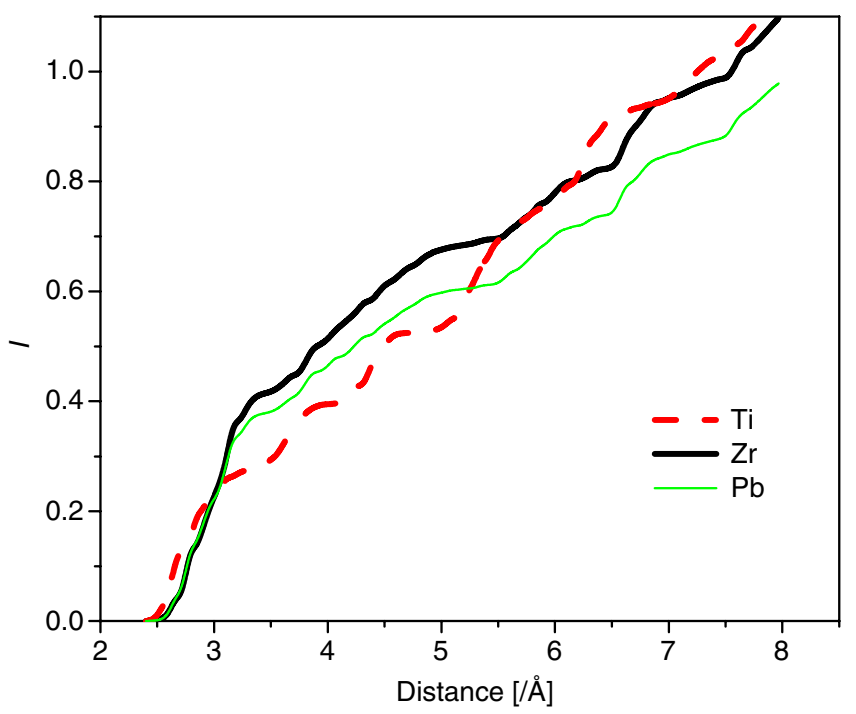

Figure 5. The integrated absolute difference, $I$, between the oxygen-oxygen RDFs of the undamaged and damaged as a function of distance. $\mathrm{Gd}_{2} \mathrm{Ti}_{2} \mathrm{O}_{7}$ red (dashed) line, $\mathrm{Gd}_{2} \mathrm{Zr}_{2} \mathrm{O}_{7}$ black (thick solid) line, $\mathrm{Gd}_{2} \mathrm{~Pb}_{2} \mathrm{O}_{7}$ green (thin solid) line.

for the Ti than for the $\mathrm{Zr}$ compound. This is of course a small difference but nevertheless this measure, unlike those based on oxygen displacements considered earlier, at least suggests that overall the loss of oxygen order is at least comparable in the Ti to that in the $\mathrm{Zr}$ compound, due to the nature of the RDFs at larger rather than shorter separations.

It is worthwhile here to comment on ionic conductivity measurements of the $\mathrm{ZrO}_{2}-\mathrm{Gd}_{2} \mathrm{O}_{3}$ system [34]. The pyrochlore $\mathrm{Gd}_{2} \mathrm{Zr}_{2} \mathrm{O}_{7}$ shows enhanced conductivity relative to that of the defect fluorite phases, which bound it on both sides in the phase diagram. The pyrochlore structure not only contains A and B ions on separate sublattices but the seven oxygen ions per formula unit in the unit cell also fully occupy two sublattices (48f and $8 \mathrm{~b}$ ). Unlike the defective fluorite structure there is an ordered arrangement of oxygen vacancies, with the so-called 8a site vacant. The ionic conductivity is due to intrinsic disorder of oxygen ions between the occupied 48f and empty 8a sites [34]. The loss of order at short distances (3-5 $\AA$ ) is associated with the partial occupation of this 8 a site. Classifying the 8 a site as an additional available lattice site, rather than an interstitial site, reduces very substantially the number of oxygen defects in $\mathrm{Gd}_{2} \mathrm{Zr}_{2} \mathrm{O}_{7}$ by a factor of 3 (table 8), while the total in the Ti compound is virtually unchanged. For $\mathrm{Gd}_{2} \mathrm{Ti}_{2} \mathrm{O}_{7}$ intrinsic oxygen disorder and hence ionic conductivity is much less [35].

\section{$\mathrm{Gd}_{2} \mathrm{~Pb}_{2} \mathrm{O}_{7}$ versus $\mathrm{Gd}_{2} \mathrm{Ti}_{2} \mathrm{O}_{7}$ and $\mathrm{Gd}_{2} \mathrm{Zr}_{2} \mathrm{O}_{7}$}

We have so far concentrated on $\mathrm{Gd}_{2} \mathrm{Ti}_{2} \mathrm{O}_{7}$ and $\mathrm{Gd}_{2} \mathrm{Zr}_{2} \mathrm{O}_{7}$ for which most experimental data are available. In view of the increasing attention being paid to other pyrochlores it is of interest to consider briefly what our various models suggest for $\mathrm{Gd}_{2} \mathrm{~Pb}_{2} \mathrm{O}_{7}$. Pb is substantially heavier than $\mathrm{Ti}$ and $\mathrm{Zr}$. $\mathrm{Pb}^{4+}$ is also larger [36] than $\mathrm{Ti}^{4+}$ and $\mathrm{Zr}^{4+}$, but, consistent with its position as a post-transition metal, the ion is also highly polarizable and a significant covalent contribution to the bonding is expected.

Table 8 lists the displacements for each type of atom in $10 \mathrm{keV}$ cascades in $\mathrm{Gd}_{2} \mathrm{~Pb}_{2} \mathrm{O}_{7}$, in an analogous format to that used for $\mathrm{Gd}_{2} \mathrm{Zr}_{2} \mathrm{O}_{7}$ and $\mathrm{Gd}_{2} \mathrm{Ti}_{2} \mathrm{O}_{7}$ in tables 2 and 3. The total distance 
Table 8. Structural damage data from $10 \mathrm{keV}$ cascades in $\mathrm{Gd}_{2} \mathrm{~Pb}_{2} \mathrm{O}_{7}$ at $300 \mathrm{~K}$ and zero pressure. The PKA is a $\mathrm{U}$ ion. The table lists how many atoms of each species have moved a particular distance given in the first column from their original lattice positions. The second column is for one cascade in the [111] ('body-diagonal') direction, while the third column lists the mean values for all eight cascades in $\langle 111\rangle$ directions.

\begin{tabular}{|c|c|c|c|c|c|c|}
\hline \multirow{4}{*}{$\begin{array}{l}\text { PKA direction } \\
\text { Band }(\AA)\end{array}$} & \multicolumn{4}{|c|}{ [111] direction } & \multicolumn{2}{|c|}{$\langle 111\rangle$} \\
\hline & \multicolumn{6}{|c|}{ Displaced } \\
\hline & \multicolumn{3}{|c|}{ Species } & \multicolumn{3}{|c|}{ Species } \\
\hline & $\mathrm{Gd}$ & $\mathrm{Pb}$ & $\mathrm{O}$ & $\mathrm{Gd}$ & $\mathrm{Pb}$ & $\mathrm{O}$ \\
\hline$>1$ & 0 & 0 & 0 & 0 & 0 & 0 \\
\hline $1-2$ & 0 & 0 & 166 & 0.3 & 0.8 & 94 \\
\hline $2-3$ & 4 & 3 & 211 & 4 & 1.8 & 215 \\
\hline $3-4$ & 5 & 2 & 120 & 8 & 4.8 & 137 \\
\hline $4-5$ & 4 & 2 & 48 & 1 & 0.8 & 46 \\
\hline $5-6$ & 1 & 1 & 15 & 1 & 0.8 & 14 \\
\hline $6-7$ & 1 & 0 & 11 & 0.3 & 0.8 & 13 \\
\hline $7-8$ & 0 & 0 & 0 & 0 & 0 & 3 \\
\hline $8-9$ & 0 & 1 & 3 & 0 & 0.3 & 2 \\
\hline $9-10$ & 0 & 0 & 2 & 0 & 0 & 0.8 \\
\hline$\ldots$ & $\ldots$ & $\ldots$ & $\ldots$ & $\ldots$ & $\ldots$ & $\ldots$ \\
\hline Total & 17 & 8 & 506 & 14 & 10 & 533 \\
\hline $\begin{array}{l}\text { Final distance of PKA } \\
\text { from starting position }(\AA)\end{array}$ & & & 91 & & & 85 \\
\hline
\end{tabular}

travelled by the PKA is comparable in all three compounds. $\mathrm{In}_{\mathrm{Gd}_{2}} \mathrm{Zr}_{2} \mathrm{O}_{7}$ the $\mathrm{U}$ atom in all our cascades finally occupied a $\mathrm{Zr}$ site, whereas in the $\mathrm{Ti}$ and the $\mathrm{Pb}$ compounds both cation sites were occupied by the $U$ at the end of the simulation in different cascades as the occupancy of a Gd site was $\approx 3$ more likely than a $\mathrm{Ti}$ or $\mathrm{Pb}$ one. The total number of displacements in the $\mathrm{Pb}$ system lies between those in the other two systems and the detailed displacement pattern is more similar to that of $\mathrm{Gd}_{2} \mathrm{Zr}_{2} \mathrm{O}_{7}$ than $\mathrm{Gd}_{2} \mathrm{Ti}_{2} \mathrm{O}_{7}$ with a large number of ions displaced by 1-2 $\AA$. Again the total numbers of atoms not located at lattice sites after the cascade (table 7) reflects the same trends as these totals. Classifying the 8a site as an additional available lattice site, rather than an interstitial site, reduces very substantially (table 7) the number of oxygen defects in $\mathrm{Gd}_{2} \mathrm{~Pb}_{2} \mathrm{O}_{7}$ by a factor of 11 , to a total well below that of the $\mathrm{Zr}$ pyrochlore, and even below that of $\mathrm{Gd}_{2} \mathrm{Ti}_{2} \mathrm{O}_{7}$.

Turning to the oxygen-oxygen radial distribution function and how it changes as a result of damage (figures 4 and 5), we see that the difference plot (figure 4) has a closer resemblance to that of $\mathrm{Gd}_{2} \mathrm{Zr}_{2} \mathrm{O}_{7}$ than $\mathrm{Gd}_{2} \mathrm{Ti}_{2} \mathrm{O}_{7}$. The integral measure of the loss of order shown in figure 5 is such that the total integral is approximately $13 \%$ less for the $\mathrm{Pb}$ than for the $\mathrm{Zr}$ compound. Thus this particular measure, which puts more weight on behaviour at larger oxygen-oxygen separations unlike those based on oxygen displacements or the total number of interstitials, suggests that overall the loss of oxygen order is least in the $\mathrm{Pb}$ pyrochlore of the three materials studied.

\section{Discussion and conclusions}

Why do $\mathrm{Gd}_{2} \mathrm{Ti}_{2} \mathrm{O}_{7}, \mathrm{Gd}_{2} \mathrm{Zr}_{2} \mathrm{O}_{7}$ and $\mathrm{Gd}_{2} \mathrm{~Pb}_{2} \mathrm{O}_{7}$ show different behaviour in our cascade simulations, and how might this be related to the extent of damage by radiation? Is it the 
mass of the transition metal or a feature of the bonding (determined chiefly in turn by the bond strengths $\mathrm{Ti}-\mathrm{O}, \mathrm{Zr}-\mathrm{O}$ and $\mathrm{Pb}-\mathrm{O}$ as reflected in the different interatomic potentials) that is playing a crucial role? We have already seen that an advantage of simulation is the ability to carry out calculations on hypothetical compounds in order to decouple size (potential-based) and mass effects. Our simulations here have shown the importance of the mass, which is not included in correlations such as that of Sickafus et al [13]. It may well be that in some series of chemically similar compounds there is a correlation between the masses of the ions and the antisite defect energy, but in others this may not necessarily be so.

The total number of oxygen atoms displaced is much larger than that of the cations (as also noted [26] in simulations of cascades in $\mathrm{La}_{2} \mathrm{Zr}_{2} \mathrm{O}_{7}$ ) consistent with a much lower threshold displacement energy for O. With the low-energy PKAs considered here, the final total of displaced cations is low. Most of the displaced cations occupy an equivalent crystallographic site. Only very few cations (at most one in each cell) move to occupy an oxygen site. Cation displacement threshold energies in $\mathrm{Gd}_{2} \mathrm{Ti}_{2} \mathrm{O}_{7}$ are significantly larger than in $\mathrm{Gd}_{2} \mathrm{Zr}_{2} \mathrm{O}_{7}$, in agreement with [33].

As the RDFs show, for the cascades we have considered here both long and short range order are largely preserved, as also observed [26] for $\mathrm{La}_{2} \mathrm{Zr}_{2} \mathrm{O}_{7}$. Although many oxygen atoms are displaced from their equilibrium positions most end up occupying equivalent crystallographic sites. Anion disordering involving the greater occupancy of the 8a sites is greater in the $\mathrm{Zr}$ and $\mathrm{Pb}$ compounds as shown by the larger occupancy of this $8 \mathrm{a}$ site; there is partial occupancy of this site in the fluorite rather than the pyrochlore structure and the oxygen vacancies are disordered over the oxygen sites in addition to the cation disorder. Figure 5 hints at the possible larger loss of longer range oxygen order in the Ti compound, although the number of oxygens displaced is much smaller. The characteristics of the cation and anion disorder differ from compound to compound, with different timescales, and largely need to be considered independently. Overall, the primary damage by our low-energy events shows the beginnings of the formation of the fluorite-like phase, rather than amorphization per se, though this is less for the Ti compound.

What materials are likely to be resistant to radiation-induced amorphization? This complex issue continues to be a subject of considerable debate (e.g., [37] and [38]) and ab initio prediction of resistance of a new material is in general still not possible. It appears particularly important to consider the healing process rather than activation barriers to damage creation and a useful connection in this context is that between resistance and glass-forming ability [39]. For example, silicates, which readily form glasses, amorphize readily, consistent with the formation of disordered covalently bonded silicate networks. Even where glasses are not formed, such as with the pyrochlores studied here, the larger the polarizing power of the cation, the greater the degree of covalency and preference for directional bonding. The more pronounced is the tendency for directional bonding, oxygen-metal-oxygen and metal-oxygen-metal bond linkages [37] may provide stabilization of the damaged state and an associated activation barrier to the healing process, which must necessarily involve the breaking of a bond with an appreciable degree of directional character. In more ionic solids there are no preferential directions for bonding and movement of ions in the healing process is not hindered in this way. $\mathrm{Gd}_{2} \mathrm{Ti}_{2} \mathrm{O}_{7}$ is less resistant to amorphization than $\mathrm{Gd}_{2} \mathrm{Zr}_{2} \mathrm{O}_{7}$, consistent with this trend. Similarly the titanates $\mathrm{Sm}_{2} \mathrm{Ti}_{2} \mathrm{O}_{7}, \mathrm{Eu}_{2} \mathrm{Ti}_{2} \mathrm{O}_{7}$ and $\mathrm{Y}_{2} \mathrm{Ti}_{2} \mathrm{O}_{7}$ are all amorphized relatively easily $[3,8,14]$ whereas the zirconates $\mathrm{Sm}_{2} \mathrm{Zr}_{2} \mathrm{O}_{7}, \mathrm{Er}_{2} \mathrm{Zr}_{2} \mathrm{O}_{7}$ and $\mathrm{Nd}_{2} \mathrm{Zr}_{2} \mathrm{O}_{7}$ are not [14, 17]. In this context it is interesting that $\mathrm{Y}_{2} \mathrm{Sn}_{2} \mathrm{O}_{7}$ is very resistant to radiation [40], and much more so [40] than $\mathrm{La}_{2} \mathrm{Sn}_{2} \mathrm{O}_{7}$, consistent with ionic radii considerations and antisite defect energies calculated using an ionic model [15] but not the covalency argument in its most basic form since Sn is appreciably less electropositive than Ti or $\mathrm{Zr}$. 
How do these trends relate to the simulations? Overall our calculations suggest the connection between ease of damage and the formation of defect cascades over the first few picoseconds is more complex than anticipated hitherto. Different measures of damage (displacements, defect totals, radial distribution functions) need careful consideration. The simulations see no direct amorphization but rather a transition to the fluorite structure which is more pronounced for the $\mathrm{Zr}$ compound (as well as the $\mathrm{Pb}$ pyrochlore) than the Ti system, which contains a smaller number of antisite defects, and although fewer oxygens are displaced by a small distance, there are hints that overall there is a larger loss of order, as shown in figure 5. The total number of displaced atoms is largest for the $\mathrm{Zr}$ pyrochlore of the three studied, but the loss of long range order as indicated by the change in the oxygen-oxygen radial distribution indicates this is comparable or less for the $\mathrm{Zr}$ than the Ti pyrochlore. Of the three systems studied the integrated radial distribution measure is least for the $\mathrm{Pb}$ system, which bears a closer resemblance to the $\mathrm{Zr}$ than the $\mathrm{Ti}$ pyrochlore. The transition to the fluorite structure appears more pronounced for the $\mathrm{Zr}$ and $\mathrm{Pb}$ compounds than the $\mathrm{Ti}$, as shown by the occupancy of the 8 a site following the cascades.

Covalency arguments in their simplest form would indicate that the $\mathrm{Pb}$ compound would be readily amorphized because of the activation energies of the healing process. Given the resistance observed for the Sn pyrochlore, which suggests that the covalency term does not dominate, it is tempting to suggest that the $\mathrm{Pb}$ compound too will be resistant to amorphization, despite the low electropositivity of $\mathrm{Pb}(\mathrm{IV})$. More experiments would clearly be extremely useful here.

For use as a host phase for actinides, the ease of incorporation of the large actinide ion in the pyrochlore structure is an important issue. Thus we have also examined solution energies for $\mathrm{UO}_{2}$ in the three pyrochlores using reaction schemes analogous to those of Cleave et al [41] for $\mathrm{PuO}_{2}$ and in particular the enthalpies of the most favourable reaction:

$$
4 \mathrm{UO}_{2}+2 \mathrm{Gd}_{\mathrm{Gd}}+2 \mathrm{X}_{\mathrm{X}} \rightarrow 2 \mathrm{U}_{\mathrm{Gd}}^{\bullet}+2 \mathrm{U}_{\mathrm{X}}^{\prime}+\mathrm{Gd}_{2} \mathrm{X}_{2} \mathrm{O}_{7} \quad(\mathrm{X}=\mathrm{Ti}, \mathrm{Zr}, \mathrm{Pb})
$$

which is written in standard Kröger-Vink notation [42]. See reference [41] for further details of other possible solution mechanisms. Consistent with Goldschmidt's rule, the calculated solution energies decrease from $\mathrm{Ti}$ to $\mathrm{Zr}$ to $\mathrm{Pb}$, with the lowest energy for the $\mathrm{Pb}$ pyrochlore.

We caution that our simulations have been limited to small initial PKA energies because of the problem of cascade overlap. While molecular dynamics simulations include crystal structure effects and a realistic treatment of atomic movements during the cascade, we are restricted by the size of the simulation cell. In addition, as pointed out in [21], the creation of a defect cascade is only part of the process of the formation of the damaged state. Our simulations, due to the short timescale, are not able to probe the healing process and determine the ultimate fate of the interstitial ions and vacancies (i.e. the formation of defect clusters, dislocations) and further work is required. Nevertheless, we might expect thermal annealing via order-disorder in $\mathrm{Gd}_{2} \mathrm{Zr}_{2} \mathrm{O}_{7}$ (which is an ionic conductor) and thus also in $\mathrm{Gd}_{2} \mathrm{~Pb}_{2} \mathrm{O}_{7}$ to be faster than for structural recovery in $\mathrm{Gd}_{2} \mathrm{Ti}_{2} \mathrm{O}_{7}$. Overall more experiments are urgently needed and it will be interesting to try and build up correlations between ease of damage formation and ease of amorphization with measures calculated not in static calculations but directly from molecular dynamics simulations of the type presented here. In addition, $a b$ initio studies such as those in [38] should provide greater insights into the link between the chemical bonding and damage creation. In the context of the variation of the damage and healing processes with, for example, mass, defect energies and bond strength, a simpler set of compounds worthy of study are the alkaline-earth oxides $\mathrm{MgO}, \mathrm{CaO}, \mathrm{SrO}$ and $\mathrm{BaO}$.

We end with further important caveats. We also carried out various cascade simulations in all three compounds at higher temperature, $500 \mathrm{~K}$, to compare the damage overall to that 
at $300 \mathrm{~K}$. Although structurally and geometrically the damage looked the same, at higher temperature the PKA trajectory was longer and the damage was more extensive in terms of totals of displaced native atoms. Real waste-forms containing used nuclear fuel or highly contaminated derivatives are 'hot' $(\approx 500 \mathrm{~K})$ and the damage dynamics is more pronounced from that at low temperatures $(\approx 300 \mathrm{~K})$. In addition, our simulations have neglected electronic effects entirely.

\section{Acknowledgments}

ITT acknowledges support from NERC. The work was also supported by two JREI awards (the Mott (RAL) and Dirac (Bristol) supercomputer clusters). Useful discussions with Kostya Trachenko (Cambridge) are gratefully acknowledged.

\section{References}

[1] Pillay K K S 1996 Radwaste 60

[2] Taubes G 1994 Science 263629

[3] Wang S X, Wang L M, Ewing R C and Govindan Kutty K V 2000 Nucl. Instrum. Methods Phys. Res. B 169135

[4] Wang S X, Begg B D, Wang L M, Ewing R C, Weber W J and Govindan Kutty K V 1999 J. Mater. Res. 144470

[5] Gupta H C, Brown S, Rani N and Gohel V B 2001 J. Raman Spectrosc. 3241

[6] Hess N J, Begg B D, Conradson S D, McCready D E, Gassman P L and Weber W J 2002 J. Phys. Chem. B 1064663

[7] Lian J, Wang L, Chen J, Sun K, Ewing R C, Matt Farmer J and Boatner L A 2003 Acta Mater. 511493

[8] Lian J, Chen J, Wang L M, Ewing R C, Matt Farmer J, Boatner L A and Helean K B 2003 Phys. Rev. B 68134107

[9] Nachimuthu P, Thevuthasan S, Engelhard M H, Weber W J, Shuh D K, Hamdan N M, Mun B S, Adams E M, McCready D E, Shutthanandan V, Lindle D W, Balakrishnan G, Paul D M, Gullikson E M, Perera R C C, Lian J, Wang L M and Ewing R C 2004 Phys. Rev. B 70100101

[10] Nachimuthu P, Thevuthasan S, Shutthanandan S, Adams E M, Weber W J, Begg B D, Shuh D K, Lindle D W, Gullikson E M and Perera R C C 2005 J. Appl. Phys. 97033518

[11] Nachimuthu P, Thevuthasan S, Adams E M, Weber W J, Begg B D, Mun B S, Shuh D K, Lindle D W, Gullikson E M and Perera R C C 2005 J. Phys. Chem. B 1091337

[12] Ewing R C, Weber W J and Lian J 2004 J. Appl. Phys. 955949

[13] Sickafus K E, Minervini L, Grimes R W, Valdez J A, Ishimaru M, Li F, McClellan K J and Hartmann T 2000 Science 289748

[14] Sickafus K E, Minervini L, Grimes R W, Valdez J A and Hartmann T 2001 Radiat. Eff. Defects Solids 155133

[15] Minervini L, Grimes R W and Sickafus K E 2000 J. Am. Ceram. Soc. 831873

[16] Minervini L, Grimes R W, Tabira Y, Withers R L and Sickafus K E 2002 Phil. Mag. A 82123

[17] Lian J, Zu X T, Kutty K V G, Chen J, Wang L M and Ewing R C 2002 Phys. Rev. B 66054108

[18] Lian J, Wang L M, Haire R G, Helean K B and Ewing R C 2004 Nucl. Instrum. Methods Phys. Res. B 18236

[19] See Panero W R, Stixrude L and Ewing R C 2004 Phys. Rev. B 70054110 for a discussion of the effect of covalency on defect formation energies in $\mathrm{Y}_{2}(\mathrm{Ti}, \mathrm{Sn}, \mathrm{Zr})_{2} \mathrm{O}_{7}$

[20] Lian J, Ewing R C, Wang L M and Helean K B 2004 J. Mater. Res. 191575

[21] Weber W J and Ewing R C 2000 Science 2892051

[22] Weber W J, Ewing R C, Catlow C R A, Diaz de la Rubia T, Hobbs L W, Kinoshita C, Matzke Hj, Motta A T, Nastasi M, Salje E K H, Vance E R and Zinkle S J 1998 J. Mater. Res. 131434

[23] Deng H F and Bacon D J 1996 Phys. Rev. B 5311376

[24] Delaye J M and Ghaleb D 1997 J. Nucl. Mater. 24422

[25] Crocombette J-P and Ghaleb D 2001 J. Nucl. Mater. 295167

[26] Chartier A, Meis C, Crocombette J-P, René Corrales L and Weber W J 2003 Phys. Rev. B 67174102

[27] Todorov I T and Smith W 2004 Phil. Trans. R. Soc. A 3621835

[28] Allan N L and Mackrodt W C 1994 Phil. Mag. B 69871

[29] Allan N L and Mackrodt W C 1993 Adv. Solid State Chem. 3221

[30] Allan N L and Mackrodt W C 1994 Mol. Simul. 1289

[31] Purton J A and Allan N L 2002 J. Mater. Chem. 122923

[32] Sleight A W 1969 Inorg. Chem. 81807 
[33] Devanathan R and Weber W J 2005 Appl. Phys. 980861110

[34] van Dijk M P, de Vries K J and Burggraaf A J 1983 Solid State Ion. 9/10 913

[35] Tuller H L 1994 J. Phys. Chem. Solids 551393

[36] Shannon R D 1976 Acta Crystallogr. A 32751

[37] E.g. Trachenko K 2004 J. Phys.: Condens. Matter 16 R1491 and references therein.

[38] Trachenko K, Pruneda J M, Artacho E and Dove M T 2005 Phys. Rev. B 71184104

[39] Wang S X, Wang L M, Ewing R C and Doremus R H 1998 J. Non-Cryst. Solids 238198

Wang S X, Wang L M, Ewing R C and Doremus R H 1998 J. Non-Cryst. Solids 238214

[40] Lian J, Wang L and Ewing R C 2002 Mater. Res. Soc. Symp. Proc. Series 757730

[41] Cleave A, Grimes R W and Sickafus A 2005 Phil. Mag. 85967

[42] Kröger F A and Vink H J 1956 Solid State Phys. 3307 